\title{
McLuhan desdobrado: teorías, conceitos, tecnologías e
} rupturas

\section{Spread McLuhan: theories, concepts, technologis and ruptures}

\section{- Osvando de Morais}

Universidade Estadual Paulista, Brasil

$\left(\begin{array}{l}\text { Fecha de recepción: } 21 \text { de noviembre de } 2019 \\ \text { Fecha de aprobación: } 1 \text { de enero de } 2020\end{array}\right)$

DOI: http://dx.doi.org/10.15304/ricd.3.11.6419

\section{NOTAS BIOGRÁFICAS}

Osvando de Morais é pós-doutor em Teorias da Comunicação e Hermenêutica pela FAAC -UNESP, Campus de Bauru. Doutor em Ciências da Comunicação pela ECA - USP. Professor Assistente Doutor na Universidade Estadual Paulista - UNESP, nos programas de graduação em Jornalismo, Pósgraduação em Mídia e Tecnologia e Pós-graduação em Comunicação.

Contacto: osvando.j.morais@unesp.br

\section{Resumen}

Na trajetória de Marshall McLuhan, conceitos fundamentais como "os meios como extensões do homem" e "o meio é a mensagem" representam muito mais do que uma revolução. São sínteses e rupturas. Traço de uma revolução tecnológica travada naquele contexto, meados do século XX. As últimas conferências e entrevistas de McLuhan revelam outra face muito importante do pensador, verdadeiros diagnósticos das dificuldades de se lidar com um universo como o do autor. Ressaltase, acima de tudo, sua sensibilidade vanguardista, aplicada aos Media com desdobramentos ainda em processos de sistematização. Suas ideias tinham a capacidade de atualizar e também de absorver as contínuas, constantes e fluidas mudanças. As últimas conferências e entrevistas estão repletas de manifestações subjetivas e de ironias sutis que esboçam uma teoria original. Este artigo busca delinear as condições em que surgiram os primeiros argumentos da construção dos conceitos principais para que deles se possa extrair o essencial como processo condutor e catalisador de suas teorias sobre imediatos da tecnologia sobre o sistema nervoso central. Por fim, os vários sentidos do pensamento de McLuhan tem amparo na filosofia, na antropologia e na literatura, presentes na atualização do conceito de "extensão", seja como órgão artificial, como prolongamento ou instrumento. Importante não se esquecer das ambiguidades das falas, que mostram outras dimensões de um McLuhan ainda pouco visto.

\section{Abstract}

In the McLuhan way, fundamental concepts like "the media as extension of man" and "the medium is the message" are more than a revolution. There are synthesis and ruptures. Traces from a technological revolution caught in that context, mid 20th Century. The last McLuhan's conferences and interviews show other face so important of this thinker, true diagnoses of the difficulties of dealing with a universe like the author's. Above all its avant-garde sensibility applied to the unfolding media still in systematization processes. His ideas had the ability to upgrade and also to absorb the continuous, constant and fluid changes. The last conferences and interviews are full of 
subjective manifestations and subtle ironies that outline an original theory. This paper seeks to outline the main concepts so that the essential as conducting and catalyzing process can be extracted from their theories about the immediates of central nervous system technology. Finally the various senses of McLuhan's thought are supported by Philosophy, Anthropology and Literature, present in the update of the concept of "extension", either as an artificial organ, as a prolongation or as am instrument. It's important not to forget the ambiguities of the speeches that show other dimensions of an unseen McLuhan.

\section{Palabras clave}

Marshall McLuhan, media, medium e mensagem, extensão, cultura, filosofía.

\section{Keywords}

Marshall McLuhan, media, médium and message, extension, cultura, philosophy.

\section{Sumario}

1. Introduçäo: considerações iniciais

2. 0 plexo mcluhinano: desdobramentos das teorias, conceitos, tecnologias e rupturas agenda 2030

3. Considerações finais

\section{Summary}

1. Introduction: initial considerations

2. The mcluhinan plexus: follow-up of theories, concepts, technologies and breakings

3. Final considerations 


\section{INTRODUÇÃO: CONSIDERAÇOES INICIAIS}

Muito já se disse sobre Mcluhan, suas ideias e teorias. No entanto, ainda há muito a ser decodificado sobre o que disse, quis dizer e que estão nas entrelinhas implícitas em sutis ironias. Isto faz crer que as afirmações filosóficas e categóricas feitas por McLuhan exigem uma leitura especial, mais sensivel e mais atenta.

Com suas ideias e teorias faz a seu modo uma supressão do tempo e do espaço, unindo filosofia, psicologia, sociologia e antropologia. Nesta sua viagem intelectual e conceitual que culminarão com grandes contribuições teóricas, detectou a necessidade de novas justificativas, diante do predomínio ou predominância da tecnologia eletrônica.

Neste sentido, a hybris ou a desmedida mcluhaniana está em desafiar a ordem estabelecida, própria dos revolucionários, para compreender os media e seus efeitos culturais, em um contexto extremamente rico, carregado de tecnologias, implicando reavaliar os órgãos de percepção ou os aparelhos perceptivos, em uma nova dinâmica com diferenças tênues entre atividade sensivel e aparelhos perceptivos, traduzindo a complexidade da linguagem e predisposição sensorial (Bourdin, 1979, p.9).

Para fazer justiça a McLuhan, basta não mais que uma simples leitura em seu referencial teórico para aparecer os grandes temas do século XX e que, camuflados em outras nomenclaturas, permanecem no atual século (McLuhan, 2015).

A começar pelos efeitos da imprensa nas mudanças sociais, passando pelo mundo impresso criado por Gutenberg, McLuhan aprofunda os estudos dos efeitos do livro no individualismo, na solidão, no isolamento e fragmentação do homem. Esta talvez seja a grande questão do século $\mathrm{XX}$, elevando a televisão como a responsável por resgatar o humano em todos esses estados.

No entanto, o pensamento teórico de McLuhan tem como base fundamental, não única, a literatura e a cultura. Seu mundo é o mundo elétrico, seu objeto é a televisão e seus efeitos a revolução cultural, política e social ou todas interligadas.

Impossível não perceber que as teorias $e$ conceitos mcluhanianos antecedem em quase meio século a idade das Redes. Muito do que se discute hoje são atualizações de McLuhan. Os conceitos são quase os mesmos, a partir de sua justificativa da revolução como um aumento constante de velocidade a suprimir tudo: tempo e espaço.

As últimas tecnologias do século $\mathrm{XX}$ trouxeram para o cenário mundial, não somente as tão esperadas inovações em tudo que havia até então, cobrindo as diversas facetas da dinâmica que envolvia o domínio total da televisão, sobrepondo-se aos outros meios. Pretende-se repensar neste ensaio os media de massa, centrando especificamente na televisão como um meio que merece todas as atenções como as teorias de Marshall McLuhan o projetam com o sentido e a importância da revolução de suas ideias, relacionadas aos meios técnicos de produção, transmissão e apropriação de mensagens, forçando, inclusive, uma reorientação metodológica, inaugurando outras vias de investigação com muitas justificativas para se repensar os processos e as práticas com inversões incriveis como por exemplo "o meio é a mensagem" .

\section{O PLEXO MCLUHINANO: DESDOBRAMENTOS DAS TEORÍAS, CONCEITOS, TECNOLOGIAS E RUPTURAS}

McLuhan, em seu início como intelectual erudito, provocou indagações sobre os caminhos e futuro não só da televisão no contexto norteamericano e canadense, mas também sobre todo o conteúdo veiculado pelos media, da forma como o conhecemos válido até hoje, como filmes, propaganda, telenovelas, programas de auditório, shows. Se a autonomia dos telespectadores era muito questionada por diversas teorias, acredita-se que houve, a partir da revolução mcluhaniana, transformação no pensamento sobre as relações dos media como emissores com seus receptores. Estas mudanças tiveram como centro a total dinâmica das influências que os media exerciam por eles mesmos, sem ter em conta as mensagens que veiculavam. Além disso, essas mudanças elevaram e muito o número de possibilidades, promovendo, por suposto, a democratização da televisão como sistema, apesar de trazer em seu bojo alterações do processo e a probabilidade de ameaçar a hegemonia das grandes redes que detém a maior parte desse lucrativo mercado. No mesmo contexto canadense e norte americano, percebe-se que um novo cenário está a se esboçar, transformando a realidade da televisão, frutos das mudanças que virão no arcabouço de novas tecnologias alardeadas por McLuhan. São ventos novos que trazem as tão 
esperadas inovações no que havia de mais original e também criativas, cobrindo as diversas facetas que envolvem a dinâmica dessa passagem do cinema para a televisão (McLuhan, 2015).

Porém, é preciso observar criteriosamente que as três idades do homem: a pré-alfabética ou tribal; a de Gutenberg ou individual e a elétrica ou retribalizada, no sistema novo, a fim de entender como esse processo se dará e o que de fato ele mudará em termos, não só de avanço teórico, mas principalmente no que diz respeito às inúmeras possibilidades de transformação de todo um sistema conhecido que urgia mudanças, num contexto em que a tecnologia estava na ordem das discussões. Estes processos provocaram na televisão a valorização de experiências já consagradas pelo cinema. Tendo ainda - no caminho dessa transformação - as múltiplas possibilidades de interação que o novo prometia, com respostas ilimitadas nesse novo panorama que se desenhava diante dos avanços que estavam por vir - espacial e temporal das comunicações massivas (Finkelstein, 1969, p.15-16).

Nesse sentido, deve-se pensar as ideias de McLuhan como uma síntese ou fusão revolúcionária da filosofia, psicologia, sociologia e também, principalmente, com a antropologia, em um processo que vive a ruptura com o surgimento da televisão que cumpriu importante papel para muitas pessoas e se constituiu no mais massivo meio para se obter informação e, também, de acesso ao lazer. No entanto, sua atuação ou programação, em muitos casos, tenha sido de gosto duvidoso. Mas, não se está aqui - neste texto - discutindo a qualidade televisa da programação que as emissoras veiculam. A ideia não é essa, mas sim analisar as possibilidades e contribuições de McLuhan no sistema midiático.

$\mathrm{Na}$ propaganda, por exemplo, em The Machanical Bride, foi um tema importante para que McLuhan pudesse pensar os media. Através da publicidade ele percebia que poderia combinar a segmentação do público que se desejava atingir e que este poderia dar respostas objetivas e imediatas. Percebeu ainda que isso poderia afetar o cotidiano das pessoas e, o mais importante, seu desejo de consumo, pois um consumidor nem muito passivo, nem ativo totalmente, mas sua capacidade de resposta seria quase imediata. Certamente, estas novas possibilidades ajudaram a pensar e a formatar um novo perfil de público mais crítico em relação ao consumo dos chamados bens simbólicos. Logo, antecipou que o público não era um mero receptor, mas um coprodutor que participa. Em tese, ele justapõe as diferentes áreas em que emerge a cultura popular como uma nova realidade tangível, no contexto geográfico, novos modos de intercâmbio entre produtor e consumidor, e a nascente interatividade, produto das extensões, tem a capacidade de transformar as realidades e seus papéis na sociedade.

Deste fluxo, nasceria uma alteração na relação entre a televisão e quem a assiste, recuperando certas sutilezas, nesta relação, brutalizadas pela imposição de conteúdo. A ideia do "meio é a mensagem" obrigará o produtor a se especializar continuamente, a fim de reformular o que produz e inserir como palavra de ordem nesse novo universo à imagem de um homem omnipresente, brindando um mundo de símbolos e frases engenhosas que definem padrões de conduta.

Assim, pode-se compreender melhor o sentido e a importância da revolução de McLuhan, extremamente dinâmica, dado que as extensões como complexo sistema proporcionará transformações em todos os níveis e isso implica ajustes não só técnicos, mas também de conteúdos veiculados como ferramenta a seu favor. Esta realidade forçou os pensadores dos media a refletirem sobre o que estão produzindo e como o público está recebendo esse produto.

As extensões, no sentido mediático, produzem um novo diálogo entre produtor e consumidor, inclusive, com todos os agentes envolvidos no processo midiático. É importante e necessário neste momento, lembrar a definição mcluhaniana de medium como qualquer tecnologia que "crie extensões". Tal discussão é necessária em virtude de apontar novos caminhos para se pensar os media como um todo. Além disso, fica evidente que será preciso repensar os modos de produção, veiculação e, sobretudo a apropriação de mensagens pelo receptor. Esta abordagem inaugurou outras linhas de investigação ao explorar uma nova variedade de ideias e, também, analisar os efeitos da técnica, forçando o surgimento das novas teorias que justificaram e repensaram os processos e as práticas mediáticas, necessárias para fundamentar o pensamento sobre as trocas de mensagens, presentes na dinâmica social, representando e aglutinando simbolicamente o mundo, pois os mass media, como o próprio nome sugere, aglutinam o público extensivo à condição de massa (McLuhan, 2015 ).

McLuhan percebeu que quando uma nova tecnologia penetra na sociedade satura e ao 
mesmo tempo fragmenta ou segmenta o sistema e o público. No entanto, deve-se salientar, portanto, que teorias basilares da extensão, que vão ao encontro desse novo contexto, dentro do que estava nascendo, por exemplo, a internet no final do século XX, forçosamente ganhará novas configurações. Seria interessante pensar a internet como o resultado de um processo evolutivo a partir da versão de extensões que exigiriam como em algo diverso uma nova teoria, por exemplo, com o sentido ecológico midiático para dar conta dessa evolução, a fim de que esse processo seja devidamente analisado e entendido (McLuhan, 2005, p.137-140).

Acreditamos na importância desse estudo que ao partir da análise da tecnologia como aceleração de processos, tal como foi concebida, chega ao ponto de se recuperar o passado e, assim, pensar na questão das sutilezas da linguagem, em que as pessoas estão prontas para agir, editar, transformar e, naturalmente, responder imediatamente a algum tipo de impulso ou provocação geradora de algum tipo de emoção, chegando a algum limite. Nesse sentido, é que as teorias de McLuhan poderiam vir ao encontro do contexto atual em que processos mediáticos transformaram-se em linguagem de sinais exemplificados pelo próprio McLuhan, depois em mímica, tal como pensamos ou aplicamos no cinema, teatro, jornalismo. Tudo que compõe e forma o pensamento de McLuhan é interessante porque faz com que se esqueça aspectos gerais dos media, tais como os conhecemos e, para não exagerar, trata-se de um técnica da informação.

Uma grande parte destas teorias aplicadas aos mas media detém, como base, nos efeitos dos meios sobre a sociedade e, aplicando esses efeitos e os estudos desses efeitos como processos que estendem ou prolongam algum sentido, características tão profundamente estudadas para que se chegasse ao medium que só existe devido a tudo que se relaciona a ele. 0 desenvolvimento da teoria pretendida por McLuhan não é outra coisa senão remarcar o fenômeno da técnica que cria ao seu redor e exige a prioridade de uma resposta em curto prazo, quase que imediato. Portanto, o efeito principal seria a impossibilidade de controlar os mass media eletrônicos, em processo, ocupando-se em levar às pessoas algum tipo de efeito revolucionário e extremamente provocador. No sentido não só de atualizar, mas desenvolver, no novo contexto, um entendimento amplo das possibilidades que transformarão os media, de maneira geral (McLuhan, 2015).
Todavia, costuma-se dizer, romanticamente, que a vida já é irreversivelmente composta de extensões, mas a tecnologia que está onipresente na vida das pessoas surgiu trazendo com aparência de futuro, em seu bojo, efeitos produzidos, plenamente integrados, num quase presente às culturas existentes por meio das extensões, estimulando, de certo modo, uma inserção. Se bem que essa inserção é uma questão bem mais complicada e não pretendemos discuti-la no momento, porque requer uma amplitude de abordagem que desviaria o centro de nossa análise (McLuhan, 1976, p. 21).

De certo modo, as pessoas diante dessa revolução tecnológica, nas principais cidades do mundo, apontam e atuam nesta mesma direção, uma vez que o contexto global evidencia que o homem está profundamente integrado às mídias, juntamente com as conexões que essas mesmas mídias permitem estabelecer, em quase todos os sentidos. E, retomando a discussão sobre os efeitos midiáticos que esse poder vem revolucionando na sociedade tecnológica, podemos dizer que o processo - agora, século XXI - se dá quase que individualmente e não mais como fenômeno grupal. Situação esta que torna patente à realidade, no contexto dos atuais agrupamentos humanos, visto que já nos final dos anos 80, portanto, no século passado, já se falava categoricamente no isolamento como um processo a que o homem estaria sujeito nos grandes centros urbanos.

Tal isolamento torna-se natural - inclusive por uma questão de segurança, evita-se sair de casa é a informação que chega aos lares, via web, televisão, celulares e por todos meios interativos possíveis. Agora, as experiências são quase que individuais e mesmo os compartilhamentos através da Internet ficam no plano do intangivel, virtual, à distância. Isso não significa dizer que nessas experiências não estejam explícitas nas trocas culturais e processos de persuasão e convencimento, questões que levam a analisar a eficácia das ideias de McLuhan.

Assim, é preciso olhar para as várias abordagens dos media, principalmente as que discutem a vulnerabilidade ou invulnerabilidade das pessoas, diante de seus efeitos, não só na vida das pessoas que estão se relacionando em grupo, mas daquelas que estão em processo de isolamento. As próteses, sejam elas pequenas ou não tão pequenas, adaptáveis a óculos, joias, canetas, dissimuladas ou inseridas, incrustadas nos ouvidos, se tornarão a grande porta para a teoria mcluhaniana dos efeitos. E, assim, pensa 
nos efeitos dos mass media, nas dimensões desses efeitos, sem esquecer que McLuhan pensou a televisão como um artefato, uma máquina que codifica e transmite mensagens com sons e imagens, desenvolvendo e evoluindo continuamente, as suas qualidades técnicas. Em outro momento, devemos entender que a televisão é uma indústria e, como uma indústria, está cheia de intenções - sejam elas empresariais, ideológicas ou culturais, e essas intenções estão principalmente projetadas, principalmente, nas mensagens publicitárias que alimentam essa mesma indústria.

A teoria de McLuhan aplicada à publicidade é clara: a televisão é constituída de um conjunto de conteúdos construídos de vários sentidos, sejam comerciais, culturais ou ideológicos. $E$ as análises nos levam a refletir sobre esses conteúdos, pois quase todos têm acesso a eles, principalmente as crianças que passam muitas horas assistindo aos programas, consumindo muito televisão, e neste consumo está a possibilidade de se avaliar os efeitos desses media, válidos também para a internet. É fácil perceber que todo telespectador constrói indagações, constrói perguntas a necessitar de respostas.

Voltando às ideias de McLuhan, o conceito de extensão se constitui em um enorme canal de participação para esse público a fim de se chegar às respostas, isto porque esse público, repetimos, necessita destas respostas e as exigem. Sabemos que o público tem dúvidas e, quando elas surgem, são necessárias para que sejam facilitados, por exemplo, o consumo, além de suprir anseios e necessidades, sejam eles, espirituais ou básicas. É exatamente por isso que a interatividade, por meio das extensões seduz, pois atua em todos os espaços da cultura, do entretenimento ou mesmo ideológico, tornando-se mais marcante principalmente nos espaços massivos e, assim, e por isso mesmo seduz justamente pela possibilidade de representar mais pontos de convergências, nos quais as emissoras podem se apoiar como modelos de difusão cultural ou negócios envolvendo a cultura (McLuhan, 2015, p. 269).

Obviamente, muitas perguntas ficarão sem respostas, mas há questões fundamentais em nossas análises, importantes a serem colocadas em relevo: as ideias de McLuhan permanecem atuais como se estivesse antevendo um futuro próximo - com a entrada e intensificação das redes sociais interativas e, portanto, com as mídias interativas? Qual seria o ponto central a ser atualizado nessas teorias? 0 centro das atenções estaria no acesso ao público ou na participação comunitária? E, como serão os conteúdos gerados pelos próprios usuários? Estas são algumas das muitas indagações que nos chegam e que só a prática dessa nova realidade, ao longo do tempo, poderá responder, incluindo o processo ecológico midiático. E quais as atualizações precisam ser feitas para que os efeitos de fato sejam realmente justificados teoricamente? A evolução pela técnica ou a passagem de uma tecnologia a outra transforma, envolve todo o sistema que compõe os mass media como a televisão e também o sistema de radiodifusão, forjando outras características. Estas características associadas à velocidade de transmissão e qualidade da imagem e do som, além dos chamados efeitos diversificados provocam um aumento muito significativo na eficiência do sistema de radiofrequência, dando possibilidades de maior oferta de conteúdos culturais e opções de serviços de toda ordem. Ampliando um pouco mais esta questão, podemos dizer que muitas destas discussões estão centradas nos modelos de negócios e produção de conteúdo, na legislação, na estética, na programação e na cultura efetivamente televisiva. Dentro destas abordagens, percebe-se, ainda, que há uma implementação ou uma possibilidade de melhoria, cada vez mais rápida, que significa realmente uma revolução dos mass media.

Esta questão com seus desdobramentos, certamente, será o centro de nossa atenção, voltando um pouco mais ao processo em que se baseia a informação. É, nesse contexto, que ressaltamos a apropriação de nossos sentidos através das extensões, ligadas ou não diretamente ao sistema nervoso central, à apropriação de novos valores estéticos, dentro da supremacia do audiovisual nominada por McLuhan. Além de alterar também os modos de apreensão do conteúdo, talvez, a grande contribuição das ideias mcluhanianas seja - de fato - a possibilidade de se pensar os prolongamentos como a passagem do homem fragmentado de Gutenberg ao homem integral dos media eletrônicos como interação entre os media e com outros homens que também estão em sintonia de maneira permeável (McLuhan, 2005, p. 90).

É bom ressaltar que esta permeabilidade, ao ser adotada como mais uma possibilidade, não ficará restrita a simples ampliação do sistema nervoso central, mas será algo mais amplo, diversificado, dinâmico. A proposta teórica de McLuhan leva a crer que, na construção de um espaço mediático realmente democrático, o usuário poderá não somente assistir, mas produzir conteúdos e inseri-los no medium de 
massa de sua escolha. Será deste processo que sairão as novas linguagens e as novas produções, ou a nova linguagem como síntese de linguagens como caminho para atualização teórica.

$\mathrm{Na}$ atualidade, os media realizam um diálogo multidirecional e abrem espaço para uma interação entre os media. Atingem a vida cotidiana das pessoas, justificando o conceito de mídia de McLuhan como "tudo que se relaciona com o meio". A grade de programação procura - dentro do possível - entreter, recriar a realidade e tirar os media da atual condição que, como a televisão não mudou completamente para uma realidade multidirecional, é pouco dissimulada e integrada tecnicamente, estabelecendo um diálogo no imenso mar informativo, exigindo, de fato, ajustes técnicos e uma nova postura que permitirá incorporar o homem em toda a sua humanidade. No sentido mcluhaniano, é o de levar cada pessoa ao mundo dos mas media eletrônicos e não apenas buscar informações, como ocorreu, num primeiro momento, com a televisão. Uma saída interessante seria buscar soluções a partir da participação ativa e assim atender as necessidades reais do telespectador, quando este preenche os espaços pela interatividade, permitindo encontrar soluções para os problemas que o aflige (McLuhan, 2015, p 307309 ).

Para McLuhan só assim a televisão poderá aprimorar e evoluir como linguagem poderá chegar daqui a algum tempo ao ideal como medium de massa interativa. Além disso, deve-se relembrar que uma das características de um medium de massa é o fato de uma única informação partir de um único ponto para milhões de receptores ao mesmo tempo. Assim, ressaltamos que a televisão não mudará as características gerais dos media de massa, mas poderá se democratizar como veículo - não por trazer conteúdos em quantidade descomunal para um grande público, mas por mantê-lo alienado sempre da realidade social e política.

No entanto, mesmo alienado tem a capacidade de dar respostas imediatas ou simultâneas através da televisão. McLuhan usou as histórias policias para pensar teorias que explicassem, e ao mesmo tempo justificassem estes processos rápidos de mudanças de comportamento. Por exemplo, os conceitos de extensão, prolongamentos, agilidade e trocas culturais estão sempre presentes quando se pretende chegar à essência propriamente dita da revolução mcluhaniana. Um dos temas mais desenvolvido por McLuhan no campo da televisão, são os efeitos dos meios como extrema relevância por atingirem as questões essenciais dos indivíduos e das populações.

Aproximando as discussões sobre as mídias com suas potencialidades, pode-se dizer que os efeitos invisíveis como os prolongamentos do sistema nervoso central, aplicados ao telespectador, devem ser repensados e justificados em termos teóricos de atualização teórica.

Neste sentido, não seria exagero propor um retorno às ideias de McLuhan e Harold Innis ao iniciarem os estudos não apenas dos efeitos da tecnologia forneceram elementos para revolucionar, drasticamente, a forma de fazer televisão, justificando, portanto, pensar todos os sentidos e maneiras padronizadas de receber informação e outros conteúdos. Deste modo, Schettino (2007) acrescenta que o atual modismo da palavra extensão vem com o sentido de dotar o receptor de um ou vários media da competência de reagir a ele em processo contínuo. As ações deste telespectador estão carregadas de significados subjetivos que traduzem a sua conduta e também a dos media com os quais interage, ultrapassando as fronteiras da subjetividade como processo de interpretação da conduta dos outros, para se chegar à intersubjetividade.

\section{CONSIDERAÇÕES FINAIS}

Os vários conceitos que McLuhan criou estão ainda em uso e certamente demandarão a necessidade de mais alguns anos de experiências e amadurecimento para se chegar à sua abrangência, ou melhor, à sua essência que inclui atualizações no contexto do século XXI. Mas seus sentidos imediatos, hoje, encontram-se na capacidade do telespectador, não só de assistir televisão, mas também de participação quando executa um papel verdadeiramente ativo no processo midiático.

Estes conceitos, obviamente, como proposta ainda nova, foram muito pouco explorados dentro de suas múltiplas possibilidades. Indagam-se quais seriam os limites das teorias de McLuhan em decorrência da amplitude das capacidades de suas ideias, possivelmente derivadas de seu repertório inventivo próprio. Estamos a lidar com uma tecnologia que inova de maneira rápida, e suas potencialidades ainda perduram como incógnitas no campo de conhecimento do homem comum. 
As possíveis respostas dependerão das futuras práticas e de seus resultados.

Parece-nos ser um bom começo comparar a televisão com a Internet na utilização das teorias e conceitos mcluhanianos, incorporando os resultados dos estudos dos efeitos, aplicados aos media atuais que deverão aparecer em breve. Seria interessante se aparecessem juntamente com teorias que dessem conta e que fundamentassem as ações e efeitos provocados, não somente como fenômenos estatísticos, mas como resultados. É temeroso pensar, sem a necessária cautela, a televisão neste momento de plena ação prática e mudanças contínuas. Pode-se correr o risco de exercício de mera futurologia.

No século atual, as mudanças tecnológicas atingem nossa capacidade de ler e perceber e ainda os nossos modos de ver e fazer televisão. Os argumentos disponíveis são apenas uma solução paliativa e momentânea à grande maioria das análises dos produtos televisivos que serão veiculados ou exibidos em tela com formatos e graus diversos (McLuhan, 2005, p.87).

Como McLuhan, acredita-se que a televisão revolucionará ainda em novas plataformas convergentes. Os exemplos são convincentes e ilustrativos, mas carecem de análises mais aprofundadas das questões tecnológicas, sociais e históricas que permeiam e envolvem século XXI. Algumas experiências poderiam ajudar a compreender melhor, no que diz respeito aos fenômenos mesclados à apreensão, extensão e próteses como prolongamentos de sentidos, projetados nas análises da televisão em seu momento atual de enfrentamento com a internet, segmentada em redes e pelos canais específicos (McLuhan, 2005, p.73).

Acreditamos não existir uma única teoria capaz de subsidiar todos os fenômenos dos media e especialmente os televisivos. Somente as experiências que ainda estão sendo realizadas, ou por vir, trarão respostas. Na atual circunstância, a televisão é classificada como um mix de mídias convergentes, incluindo todo o seu entorno e relações tecnológicas, talvez seja possível pensar em de um mix de teorias para dar conta da multiplicidade de fenômenos. Estas são as intersecções mcluhanianas a exigir um diálogo constante entre as suas teorias e conceitos, compreendendo os media como forma política, como formas artísticas, como batalha e como mensagem. Por outro lado, a natureza interdisciplinar das ideias de McLuhan aponta para alguns caminhos na superação dos obstáculos às justificativas presentes desde o começo de existência.

1- A transformação da sociedade é feita através de mensagens trocadas entre os indivíduos e estes, por sua vez, com os meios massivos, com tecnologia como extensões, revolucionando a sociedade e a cultura, que representam e refletem simbolicamente o mundo.

2- Antes, os mass media, como o próprio termo já denota, aglutinavam públicos. Agora, os públicos são fragmentados em segmentos estanques, cada qual a fazer sua própria escolha: selecionando e/ou editando e construindo sua programação particular, a partir daquela comum produzida e enviada a todos.

3- É imperioso pensar as teorias e conceitos mcluhanianos que objetivam dar conta das análises dos processos atuais em que as práticas das relações interpessoal, grupal e coletiva ganham novas configurações.

\section{REFERENCIAS BIBLIOGRÁFICAS}

- Bourdin, A. (1979). McLuhan. São Paulo: Melhoramentos.

- Finkelstein, S. (1969). McLuhan : a filosofia da insensatez. Rio de Janeiro: Paz e Terra,

- McLuhan, M. (1966). Os meios de comunicação como extensões do homem. São Paulo: Cultrix.

- McLuhan, M. (2005). McLuhan por McLuhan. conferências e entrevistas. Rio de Janeiro: Ediouro.

- McLuhan, M. (2009). Compreender-me. conferências e entrevistas. Lisboa: Relógio D’água.

- McLuhan, M. (2015). Inédito/Marshal McLuhan. Ciudad Autónoma de Buenos Aires: La Marca Editora.

- Schettino, P. (2001). Diálogos sobre a tecnologia do cinema brasileiro. São Paulo: Ateliê Editorial. 